\title{
Correcting Thornthwaite potential evapotranspiration using a global grid of local coefficients to support temperature-based estimations of reference evapotranspiration and aridity indices
}

\author{
Vassilis Aschonitis ${ }^{1}$, Dimos Touloumidis ${ }^{2}$, Marie-Claire ten Veldhuis ${ }^{2}$, Miriam Coenders-Gerrits ${ }^{2}$
}

$5 \quad{ }^{1}$ Soil and Water Resources Institute, Hellenic Agricultural Organization - DEMETER, Thessaloniki - Thermi, 57001, Greece ${ }^{2}$ Water Resources Section, Delft University of Technology, Stevinweg 1, 2628 CN Delft, the Netherlands

Correspondence to: Vassilis Aschonitis (v.aschonitis@swri.gr)

\begin{abstract}
Thornthwaite's formula is globally an optimum candidate for large scale applications of potential evapotranspiration and aridity assessment at different climates and landscapes since it has the lower data requirements compared to other methods and especially from the ASCE-standardized reference evapotranspiration (former FAO-56), which is the most data demanding
\end{abstract} method and is commonly used as benchmark method. The aim of the study is to develop a global database of local coefficients for correcting the formula of monthly Thornthwaite potential evapotranspiration $\left(E_{p}\right)$ using as benchmark the ASCEstandardized reference evapotranspiration method $\left(E_{r}\right)$. The validity of the database will be verified by testing the hypothesis that a local correction coefficient, which integrates the local mean effect of wind speed, humidity and solar radiation, can

15 improve the performance of the original Thornthwaite formula. The database of local correction coefficients was developed using global gridded temperature and $E_{r}$ data of the period 1950-2000 at 30 arc-sec resolution ( $1 \mathrm{~km}$ at equator) from freely available climate geodatabases. The correction coefficients were produced as partial weighted averages of monthly $E_{r} / E_{p}$ ratios by setting the ratios' weight according to the monthly $E_{r}$ magnitude and by excluding colder months with monthly values of $E_{r}$ or $E_{p}<45 \mathrm{~mm} \mathrm{month}^{-1}$ because their ratio becomes highly unstable for low temperatures. The validation of the correction coefficients was made using raw data from 525 stations of Europe, California-USA and Australia including data up to 2020. The validation procedure showed that the corrected Thornthwaite formula $E_{p s}$ using local coefficients led to a reduction of RMSE from 37.2 to $30.0 \mathrm{~mm} \mathrm{~m}^{-1}$ for monthly and from 388.8 to $174.8 \mathrm{~mm} \mathrm{y}^{-1}$ for annual step estimations compared to $E_{p}$ using as benchmark the values of $E_{r}$ method. The corrected $E_{p s}$ and the original $E_{p}$ Thornthwaite formulas were also evaluated by their use in Thornthwaite and UNEP (United Nations Environment Program) aridity indices using as benchmark the respective indices estimated by $E_{r}$. The analysis was made using the validation data of the stations and the results showed that the correction of Thornthwaite formula using local coefficients increased the accuracy of detecting identical aridity classes with $E_{r}$ from $63 \%$ to $76 \%$ for the case of Thornthwaite classification, and from $76 \%$ to $93 \%$ for the case of UNEP classification. The performance of both aridity indices using the corrected formula was extremely improved in the case of non-humid classes. The global database of local correction factors can support applications of reference evapotranspiration and aridity indices assessment with the minimum data requirements (i.e. temperature) for locations where climatic data are limited. The global 
https://doi.org/10.5194/essd-2021-115

Preprint. Discussion started: 9 July 2021

(c) Author(s) 2021. CC BY 4.0 License.

(c) (i)

grids of local correction coefficients for Thornthwaite formula produced in this study are archived in PANGAEA database and can be assessed using the following link: https://doi.pangaea.de/10.1594/PANGAEA.932638 (Aschonitis et al., 2021).

\section{Introduction}

The assessment of potential or reference evapotranspiration is among the most important components for many hydro-climatic applications such as irrigation design and management, water balance assessment studies, and assessment of aridity classification and drought indices (Weiß and Menzel, 2008; Wang and Dickinson, 2012; McHanon, 2013; Aschonitis et al., 2017).

Such applications, and especially applications of aridity classification and drought indices (UNEP 1997; Thornthwaite, 1948; Palmer, 1965; Holdridge, 1967; Beguería et al., 2014) that are usually employed at large scales, require estimations of

40 potential or reference evapotranspiration of respective scale. The major problem in such applications is not only the limited availability of stations per se but also the limitation of many stations to provide data for a complete set of parameters (i.e. precipitation, temperature, solar radiation, wind speed, humidity). A complete set of climate parameters is prerequisite for accurate estimations of potential or reference evapotranspiration using integrated methods such as these of Penman (1948), Shuttleworth, 1993; Allen et al. (1998), Allen et al. (2005), and others which are expressions of energy balance. Unfortunately,

45 large scale applications suffer from these limitations and the common solution is to use temperature-based formulas (Thornthwaite, 1948; McCloud, 1955; Hamon 1961, 1963; Baier and Robertson, 1965; Malmström, 1969; Hargreaves et al., 1982; Camargo et al., 1999; Droogers and Allen 2002; Pereira and Pruitt 2004; Oudin et al., 2004; Trajkovic 2005, 2007; Trajkovic and Kolakovic, 2009a,b; Almorox et al., 2015; Aschonitis et al. 2017; Sanikhani et al. 2019; Quej et al., 2019; Trajkovic et al., 2020). However, extensive literature shows that temperature-based formulas are inherently of low performance

50 because temperature cannot describe properly the evaporative flux, while various studies have shown differences among the Penman-Monteith-based and temperature-based potential evapotranspiration assessments such as the one of Thornthwaite (1948), which is the most popular in aridity and drought indices applications (Sheffield et al., 2012; Dai, 2013; van der Schrier et al., 2013; Trenberth et al., 2014; Yuan and Quiring, 2014; Zhang et al., 2015; Asadi Zarch et al., 2015).

The formula of Thornthwaite (1948) was firstly proposed as internal part of the respective Thornthwaite

55 aridity/humidity index and it was calibrated based on measured monthly evapotranspiration from some well-watered grasscovered lysimeters in the eastern and central USA (Willmott et al.1985; Van Der Schrier et al., 2011). The specific formula overestimates the potential evapotranspiration in humid climates and underestimates it in arid climates (Pereira and Pruitt, 2004; Castaneda and Rao, 2005; Trajkovic and Kolakovic, 2009), and thus, a number of efforts have been made to amend the parameters or constants of the empirical formula to adapt it to various geographical zones (Jain and Sinai, 1985; Pereira and

60 Pruitt, 2004; Castaneda and Rao, 2005; Zhang et al., 2008; Bakundukize et al., 2011; Yang et al., 2017). Indicative modifications were proposed by Willmott et al. (1985) using an additional parametrization presented for mean monthly temperature above $26.5^{\circ} \mathrm{C}$ and an adjustment for variable daylight and month lengths. Camargo et al. (1999) substituted the 
mean monthly temperature by another factor called effective temperature considering the amplitude between maximum and minimum temperature. Jain and Sinai (1985) modified the constant in the general formula based on the min-max range of the

65 annual mean air temperature to calculate the evapotranspiration for semiarid conditions. Pereira and Pruitt (2004) proposed an adaptation of the Thornthwaite scheme to estimate the daily reference evapotranspiration on two contrasting environments in USA and Brazil. Castaneda and Rao (2005) recalibrated the coefficient of the general formula based on estimations of potential evapotranspiration using the FAO Penman-Monteith method in southern California. Zhang et al. (2008) used a modified formula to estimate the actual evapotranspiration in cropland, shrubland and forest located in the subalpine region of southwestern China. Bakundukize et al. (2011) used two modifications and the original Thornthwaite method to groundwater recharge estimations in the inter-lacustrine zone of East Africa. Yang et al. (2017) presented a method to quantitatively identify the differences in the spatiotemporal variabilities of global drylands between the Thornthwaite and Penman-Monteith parameterizations.

The last years, advanced interpolation techniques, climatic models and other methods have achieved to generate gridded

75 datasets of various climatic parameters (Hijmans et al., 2005; Sheffield et al., 2006; Osborn and Jones, 2014; Harris et al., 2014; Brinckmann et al., 2016; Liu et al. 2020) facilitating attempts to develop global maps of potential/reference evapotranspiration and to investigate the accuracy of formulas of reduced parameters versus benchmark methods at global scale (Droogers and Allen, 2002; Weiß and Menzel, 2008; Zomer et al., 2008; Aschonitis et al., 2017). A similar attempt is performed in this study aiming to develop a global database of local correction coefficients for the original Thornthwaite

80 formula that will better support all hydro-climatic applications and especially to support large scale applications of aridity indices, which are highly prone to data limitations. The hypothesis that is tested in this work is that a local correction coefficient that integrates the local mean effect of wind speed, humidity and solar radiation can improve the performance of the original Thornthwaite formula and to convert it at the same time to a formula of reference evapotranspiration for short reference crop.

\section{Data and Methods}

\section{$85 \quad 2.1$ Data}

The methodological steps of the next sections are used to develop a global map of local coefficients for correcting the original potential evapotranspiration formula of Thornthwaite following a calibration and a validation procedure.

The derivation/calibration procedure was performed at global scale using global gridded data from two databases. The first database of Hijmans et al. (2005) provides gridded data of mean monthly precipitation $P$ and mean monthly temperature

$90 T$ of the period 1950-2000 (WorldClim version 1.2) at $30 \mathrm{arc}-\mathrm{sec}$ spatial resolution $(\sim 1 \times 1 \mathrm{~km}$ at the equator) (Fig.1a,b). The second database is of Aschonitis et al. (2017), which provides gridded data of mean monthly reference evapotranspiration $E_{r}$ of the period 1950-2000 at five different resolutions (30 arc-sec, 2.5 arc-min, 5 arc-min, 10 arc-min and 0.5 deg) (Fig.1c). The method used for estimating $E_{r}$ is the ASCE-standardized method (former FAO-56), which estimates reference evapotranspiration for short clipped grass (Allen et al., 2005). The database of $E_{r}$ (Aschonitis et al., 2017) was built using the 
temperature from the first database of Hijmans et al. (2005) at 30 arc-sec resolution and for this reason the two gridded databases are compatible.

\section{[FIGURE 1]}

The validation procedure was performed using raw data of stations from three different databases. The first database is the CIMIS database (California Irrigation Management System - CIMIS, http://www.cimis.water.ca.gov), which includes stations from California-USA and it was selected because it provides a dense and descriptive network of stations for a specific region that combines semi-arid/temperate coastal, plain, mountain environments. In total 60 stations (Fig.2a) were used from CIMIS database that have at least 15 years of observations with a significant part of their observations after 2000. The second database is the AGBM database (Australian Government - Bureau of Meteorology, http://www.bom.gov.au). This database includes many stations from Australia and was selected because the station's network covers a large territory with a large variety of climate classes from desert to tropical climate. The selection of stations was performed in order to cover all the possible existing Köppen-Geiger climatic types (Peel et al., 2007) and altitude ranges that exist in the Australian territory. In total 80 stations were used (Fig.2b), that have at least 15 years of observations with a significant part of their observations after

110 2000. The third database is the ECAD database (European Climate Assessment \& Database, https://www.ecad.eu). This database is a network that contains more than 20,000 stations throughout Europe and provides daily observations of climatological parameters. In this study, a final number of 385 stations (Fig.2c) was selected because they contained complete data of precipitation, temperature, solar radiation, relative humidity and wind speed for a period of at least 20 years with a significant part of their observations after 2000. Some additional stations from the three databases (CIMIS, AGBM, ECAD),

115 which do not have at least 15 years of observations, were selected due to their special climate Köppen-Geiger class or the high altitude of their location). The total number of stations used in the study from the three databases is 525 and their full description is given in Table $\mathrm{S} 1$ of the Supplementary material.

\section{[FIGURE 2]}

\subsection{Derivation and validation of Thornthwaite correction coefficients for short reference crop based on ASCE- standardized method}

The monthly potential evapotranspiration $E_{p}$ using the Thornthwaite (1948) method after its adjustment for variable daylight and month lengths (Willmott et al., 1985) is estimated as follows:

$$
\begin{gathered}
E_{p}=16 \cdot\left(\frac{10 \cdot T_{\text {mean }}}{J}\right)^{a} \cdot \frac{N \cdot n}{365} \\
J=\sum_{i=1}^{12} j_{i}
\end{gathered}
$$




$$
\begin{gathered}
j_{i}=\left(\frac{T_{\text {mean }, i}}{5}\right)^{1.514} \\
\alpha=\left(6.75 \cdot 10^{-7}\right) \cdot J^{3}-\left(7.71 \cdot 10^{-5}\right) \cdot J^{2}+\left(1.79 \cdot 10^{-2}\right) \cdot J+0.492 \\
N=\frac{24}{\pi} \cdot \omega_{S} \\
\omega_{s}=\frac{\pi}{2}-\arctan \left[\frac{-\tan (\varphi) \cdot \tan (\delta)}{X^{0.5}}\right]
\end{gathered}
$$

where: $X=1-[\tan (\varphi)]^{2} \cdot[\tan (\delta)]^{2}$, if $X \leq 0$ then $X=0.00001$

$$
\delta=0.409 \cdot \sin \left(2 \cdot \pi \cdot \frac{d_{j}}{365}-1.39\right)
$$

where $E_{p}$ : the mean monthly potential evapotranspiration or potential evapotranspiration of month $i\left(\mathrm{~mm} \mathrm{month}^{-1}\right), T_{\text {mean, }, \text { : }}$ the mean monthly temperature $\left({ }^{\circ} \mathrm{C}\right), n$ : the number of days in the month, $N$ : the mean length of daylight of the days of the month (hours), $J$ : the annual heat index, $j_{i}$ : the monthly heat index, $\alpha$ : the function of the annual heat index and $d_{j}$ : the Julian day.

The benchmark method that was used for developing correction coefficients for the temperature-based method of Thornthwaite $E_{p}$ is ASCE-standardized method (former FAO-56), which estimates reference evapotranspiration from short clipped grass, as follows (Allen, et al., 2005):

$$
E_{r}=\frac{0.408 \cdot \Delta \cdot\left(R_{n}-G\right)+\frac{\gamma \cdot u_{2} \cdot\left(e_{s}-e_{a}\right) \cdot C_{n}}{\left(T_{\text {mean }}+273.16\right)}}{\Delta+\gamma \cdot\left(1+C_{d} \cdot u_{2}\right)}
$$

where $E_{r}$ : the reference evapotranspiration $\left(\mathrm{mm} \mathrm{d}^{-1}\right), \Delta$ : the slope of the saturation vapour pressure-temperature curve $\left(\mathrm{kPa}^{\circ} \mathrm{C}^{-}\right.$ $\left.{ }^{1}\right), R_{n}$ : the net radiation at the crop surface $\left(\mathrm{MJ} \mathrm{m}^{-2} \mathrm{~d}^{-1}\right), G$ : the soil heat flux density at the soil surface $\left(\mathrm{MJ} \mathrm{m}^{-2} \mathrm{~d}^{-1}\right), \gamma:$ the psychrometric constant $\left(\mathrm{kPa}^{\circ} \mathrm{C}^{-1}\right), u_{2}$ : the wind speed at $2 \mathrm{~m}$ height above the soil surface $\left(\mathrm{m} \mathrm{s}^{-1}\right), e_{s}$ : the saturation vapour pressure $(\mathrm{kPa}), e_{a}$ : the actual vapour pressure $(\mathrm{kPa}), T_{\text {mean }}$ : the mean daily air temperature $\left({ }^{\circ} \mathrm{C}\right), C_{n}$ and $C_{d}$ : constants, which vary according to the time step and the reference crop type and describe the bulk surface resistance and aerodynamic roughness. Eq. 3 can be applied for two types of reference crop (i.e. short and tall). The short reference crop (ASCE-short) corresponds to

135 clipped grass of $12 \mathrm{~cm}$ height and surface resistance of $70 \mathrm{~s} \mathrm{~m}^{-1}$ where the constants $C_{n}$ and $C_{d}$ have the values 900 and 0.34 , respectively. (Allen et al., 2005). The use of Eq.3 in daily or monthly step for short reference crop is equivalent to FAO-56 method (Allen et al., 1998) and this is how it is used in this study.

The derivation of a correction coefficient for Eq.1 using as benchmark the values of Eq.3 is performed based on the same procedure proposed by Aschonitis et al. (2017) that has been used before for developing partial weighted annual correction coefficients for Priestley-Taylor and Hargreaves-Samani evapotranspiration methods. The procedure starts with the derivation of the monthly coefficient $c_{t h, i}$ for each month $i$ based on Eq.5. Applying this procedure, twelve values of monthly $c_{t h, i}$ are produced. The 12 monthly $c_{t h}$ coefficients are then used to build mean annual coefficients. As it was mentioned in Aschonitis et al. (2017), the efficiency of mean annual correction coefficients is mainly associated to their ability to better 
describe the larger values of the dependent variable (i.e. the values of $E_{r}$ during summer/hot months) and not the smaller values during cold period where the absolute errors $\left(e_{\mathrm{i}}=E_{r, i}-E_{p, i}\right)$ are smaller. For this reason, weighted annual averages based on the monthly $c_{t h, i}$ coefficients are estimated considering the participation weight of each month in the annual $E_{r}$. Moreover, under cold conditions, the monthly coefficients $c_{t h, i}$ may present unrealistic values that significantly affect the weighted averages. To solve this problem, threshold values for the monthly $E_{p, i}$ and $E_{r, i}$ were used before the inclusion of their $c_{t h, i}$ in the weighted average estimations. Preliminary analysis showed that when the mean monthly $E_{p, i}$ and/or $E_{r, i}$ are below $\sim 45 \mathrm{~mm} \mathrm{month}^{-1}(\sim 1.5$ $\mathrm{mm} \mathrm{d}^{-1}$ ), then unrealistic mean monthly $c_{t h, i}$ values occur (as unrealistic values are considered those, which are at least one order of magnitude larger or smaller from 1). Taking into account the above, the following procedure was performed in order to obtain a partial weighted average based on monthly $c_{t h, i}$ values after excluding those months with $E_{r}$ and/or $E_{p} \leq 45 \mathrm{~mm}$ month $^{-1}$ as follows:

$$
\begin{gathered}
c_{t h, i}=E_{r, i} / E_{p, i} \\
\text { If } E_{r, i}>45 \mathrm{~mm} \mathrm{month}{ }^{-1} \text { then } F_{r, i}=1 \text { else }=0 \\
\text { If } E_{p, i}>45 \mathrm{~mm} \mathrm{month}^{-1} \text { then } F_{m, i}=1 \text { else }=0 \\
E_{r, i}^{a d j}=E_{r, i} \cdot F_{r, i} \cdot F_{m, i} \\
A E_{r}^{a d j}=\sum_{i=1}^{12}\left(E_{r, i}^{a d j}\right) \\
C_{t h}=\sum_{i=1}^{12}\left(\frac{E_{r, i}^{a d j}}{A E_{r}^{a d j}} \cdot c_{t h, i}\right)
\end{gathered}
$$

where $c_{t h, i}$ : the monthly correction coefficient, $F_{r, i}$ : the filter function for the reference method (ASCE) with values 0 or $1, F_{m, i}$ : the filter function for the understudy model (Thornthwaite formula) with values 0 or $1, E_{r, i}^{a d j}$ : the adjusted monthly value of $E_{r, i}$ from ASCE-short method that becomes 0 when $F_{r, i}$ or $F_{m, i}$ is $0, A E_{r}^{a d j}$ : the annual sum of the monthly $E_{r, i}^{a d j}$ adjusted values, $C_{t h}$ : the annual partial weighted average (p.w.a.) of the monthly $c_{t h, i}$ coefficients for short reference crop and $i$ : the index of each month. Considering the above, the final corrected Thornthwaite formula for monthly calculations is given by the following equation:

$$
E_{p s, i}=C_{t h} \cdot E_{p, i}
$$

160 where $E_{p s, i}$ : the corrected temperature-based short reference crop evapotranspiration (mm month ${ }^{-1}$ ) of month $i$.

The above procedure was followed in order to calibrate the annual partial weighted average $C_{t h}$ (Eq.10) for every location on the globe based on mean monthly $E_{r}$ and $E_{p}$ of 1950-2000 using:

- the gridded mean monthly temperature data of Hijmans et al. (2005) that were further used to estimate the mean monthly gridded original Thornthwaite $E_{p}$ (Eq.1) for the period 1950-2000 (in the form of 12 raster datasets of $E_{p}$ for each month),

- the respective mean monthly grids of $E_{r}$ based on ASCE-standardized for short reference crop (Eq.1) from Aschonitis et al. (2017) (in the form of 12 raster datasets of $E_{r}$ for each month). 
The validation procedure with the data of the 525 stations was performed by comparing the mean monthly and the mean annual benchmark values of $E_{r}$ (Eq.4) versus the original $E_{p}$ (Eq.1) and versus the corrected $E_{p s}$ Thornthwaite formula (Eq.11) taking into account the annual partial weighted average coefficients $C_{t h}$ at the location of each station. The validation was made separately for each database of stations (ECAD, AGBM, CIMIS) but also all together using the following five statistical criteria:

$$
\begin{gathered}
M A E=\frac{1}{N} \sum_{i=1}^{N}\left|S_{i}-O_{i}\right| \\
M E=\frac{1}{N} \sum_{i=1}^{N}\left(S_{i}-O_{i}\right) \\
R M S E=\sqrt{\frac{1}{N} \sum_{i=1}^{N}\left(S_{i}-O_{i}\right)^{2}} \\
R_{S q r}=\left[\frac{\sum_{i=1}^{N}\left(O_{i}-\overline{O_{i}}\right)\left(S_{i}-\overline{S_{i}}\right)}{\sqrt{\sum_{i=1}^{N}\left(O_{i}-\overline{O_{i}}\right)^{2} \sum_{i=1}^{N}\left(S_{i}-\overline{S_{i}}\right)^{2}}}\right]^{2} \\
d=1-\frac{\sum_{i=1}^{N}\left(S_{i}-O_{i}\right)^{2}}{\sum_{i=1}^{N}\left(\left|S_{i}-\overline{O_{i}}\right|+\left|O_{i}-\bar{O}_{i}\right|\right)^{2}}
\end{gathered}
$$

where MAE: the mean absolute error, ME: the mean error, RMSE: the root mean square error, $R_{S q r}$ : the coefficient of determination and $d$ : the index of agreement, $O$ : the observed or benchmark value (i.e. $E_{r}$ ), $S$ : the simulated value by the model (i.e. $E_{p}$ or $E_{p s}$ ), $N$ : the number of observations, $i$ : the subscript referred to each observation. The value of perfect fit is 0 for the criteria MAE, ME and RMSE while is 1 for the criteria $R_{S q r}$ and $d$. The values of MAE, ME and RMSE criteria have the same units with the observed and simulated data while $R_{S q r}$ and $d$ are unitless.

\subsection{Evaluating the use of correction coefficients in aridity indices based on stations data}

The role of the new corrected formula of Thornthwaite (Eq.11) as internal parameter of aridity indices was also evaluated against the original method (Eq.1). For this purpose, the $A I_{U N E P}$ (UNEP, 1997) and $A I_{T H}$ (Thornthwaite, 1948) aridity indices were used. The difference between the two indices is that $A I_{U N E P}$ does not consider seasonality. The two indices estimated based on $E_{r}$ (Eq.4) were used as benchmark in order to compare the respective indices calculated with the original Thornthwaite $E_{p}$ (Eq.1) and the corrected $E_{p s}$ (Eq.11) using the 525 stations data. The evaluation was performed:

- by comparing the estimated aridity classes of 525 stations produced by the benchmark $A I_{U N E P}$ and $A I_{T H}$ values using $E_{r}$ versus the classes of the two indices using $E_{p}$ and $E_{p s}$, respectively.

- by comparing the respective values of the indices using 1:1 plots and the statistical metrics of Eqs.12-16.

The $A I_{U N E P}$ aridity index is the simpler method for hydroclimatic analysis and it is given by the following equation: 


$$
A I_{U N E P}=\frac{P_{y}}{E_{y}}
$$

where $P_{y}$ : mean annual precipitation (mm/year) and $E_{y}$ : mean annual potential evapotranspiration (mm/year). The values of Eq.16 are classified according to the following (UNEP, 1997; Cherlet, 2018):

- $\quad A I_{U N E P}<0.05 \rightarrow$ Hyper-arid

- $0.03 \leq A I_{U N E P}<0.2 \rightarrow$ Arid

- $0.2 \leq A I_{U N E P}<0.5 \rightarrow$ Semi-arid

- $0.5 \leq A I_{U N E P}<0.65 \rightarrow$ Dry subhumid

- $0.65<A I_{U N E P} \rightarrow$ Humid

The classes for $A I_{U N E P}>0.65$ are usually given as one humid class. The UNEP index does not consider the effect of seasonal variation of precipitation and potential evapotranspiration.

The $A I_{T H}$ aridity index is calculated as follows:

$$
\begin{gathered}
S=\sum_{i=1}^{12}\left(P_{i}-E_{i}\right) \quad \text { and } D=\sum_{i=1}^{12}\left(E_{i}-P_{i}\right) \\
A I_{T H}=100 \frac{S-0.6 D}{E_{y}}
\end{gathered}
$$

where $P_{i}$ and $E_{i}$ are the monthly precipitation and potential evapotranspiration of month $i$, respectively. $S$ (mm $\mathrm{y}^{-1}$ ) considers only the positive values of $\left(P_{i}-E_{i}\right)>0$, while $\left(P_{i}-E_{i}\right)<0$ are set 0 . In the case of $D\left(\mathrm{~mm} \mathrm{y}^{-1}\right)$, only the positive values of $\left(E_{i}-P_{i}\right)$ $>0$ are considered while for $\left(E_{i}-P_{i}\right)<0$ are set 0 . The various climatic types according to $A I_{T H}$ values are the following:

- $\quad-60>A I_{T H} \rightarrow$ Hyper-arid (HE)

- $\quad-60 \leq A I_{T H}<-40 \rightarrow$ Arid (E)

- $\quad-40 \leq A I_{T H}<-20 \rightarrow$ Semi-arid (D)

- $\quad-20 \leq A I_{T H}<0 \rightarrow$ Dry sub-humid (C1)

- $0 \leq A I_{T H}<20 \rightarrow$ Moist sub-humid (C2)

- $20 \leq A I_{T H}<40 \rightarrow$ Low Humid (B1)

- $40 \leq A I_{T H}<60 \rightarrow$ Moderate Humid (B2)

- $60 \leq A I_{T H}<80 \rightarrow$ Highly Humid (B3)

- $80 \leq A I_{T H}<100 \rightarrow$ Very Humid (B4)

- $100 \leq A I_{T H} \rightarrow$ Hyper-humid (A) 


\section{Results}

\subsection{Derivation and validation of the $C_{t h}$ correction coefficients}

The global map of the $C_{t h}$ correction coefficient was developed following the procedure described in Section 2.2 and it is given in Fig.3. The validation of the derived $C_{t h}$ coefficients was performed for each one of the three datasets of stations (CaliforniaCIMIS, Australia-AGBM, Europe-ECAD), separately, by comparing the performance of mean monthly values (Fig.S1a-f,

215 supplementary material) and the performance of mean annual values (Fig.S2a-f, supplementary material) of $E_{p}$ (Eq.1) and $E_{p s}$ (Eq.11) versus the benchmark values of $E_{r}$ (Eq.4). The statistical criteria (Eqs.12-16) for both monthly and annual comparisons for each one of the three datasets of stations are given in Table 1. The respective monthly and annual comparisons after merging all the stations from the three datasets are also presented in Fig.6a-d. From the results shown in Figs.4,5,6 and Table1, it is observed a much better performance of $E_{p s}$ compared to the original Thornthwaite formula $E_{p}$ in all cases providing not only better monthly but also better annual reference evapotranspiration estimations that approximate the values of ASCE for short reference grass.

\section{[FIGURE 3]}

\section{[TABLE 1]}

\section{[FIGURE 4]}

\subsection{Evaluating the use of $C_{t h}$ coefficient in $A_{U N E P}$ and $A I_{T H}$}

The use of $C_{t h}$ coefficients in $A I_{U N E P}$ and $A I_{T H}$ aridity indices was evaluated based on the raw data of all 525 stations (CaliforniaCIMIS, Australia-AGBM, Europe-ECAD).

The aridity classes of 525 stations given by the benchmark $A I_{U N E P}$ using $E_{r}$ were identical at $76 \%$ with the classes of the $A I_{U N E P}$ using $E_{p}$ and $93 \%$ identical with the classes of the $A I_{U N E P}$ using $E_{p s .}$. Similarly, the aridity classes of 525 stations given by the benchmark $A I_{T H}$ using $E_{r}$ were identical at $52 \%$ with the classes of the $A I_{T H}$ using $E_{p}$ and $58 \%$ identical with the classes of the $A I_{T H}$ using $E_{p s} . E_{p s}$ showed better performance compared to $E_{p}$ at correctly identifying the aridity classes in both indices. The lower percentages of success in the case of $A I_{T H}$ for both $E_{p}$ and $E_{p s}$ are due to the double number of classes of $A I_{T H}$ in comparison to $A I_{U N E P}$. Merging the $\mathrm{B}$ and A classes of $A I_{T H}$ to one Humid class, as in the case of $A I_{U N E P}$, the successful identical codes are raised to $63 \%$ for $E_{p}$ and $76 \%$ for $E_{p s}$.

The 1:1 log-log plots of $A I_{U N E P}$ using $E_{r}$ versus the $A I_{U N E P}$ using $E_{p}$ and $E_{p s}$ are given in Fig.5a,b, respectively, while the same comparisons using $A I_{T H}$ are given in Fig.6a,b. The visual inspection of Figs.5,6 clearly shows that $E_{p s}$ outperforms the $E_{p}$ in the range of non-humid classes of both $A I_{U N E P}$ and $A I_{T H}$. In order to highlight this result, the statistical metrics (Eqs.1216) were estimated after splitting the stations in two groups (non-humid and humid) based on the respective thresholds of humid classes of each index calculated using $E_{r}$ (Table 2). Table 2 verifies the better performance of $E_{p s}$ compared to $E_{p}$ in both $A I_{U N E P}$ and $A I_{T H}$ aridity indices for the non-humid classes. 
On the other hand, the statistics showed that $E_{p}$ showed better performance in both $A I_{U N E P}$ and $A I_{T H}$ aridity indices for their respective humid classes. This result is of less importance since $E_{p s}$ showed better performance compared to $E_{p}$ at correctly identifying the aridity classes in both indices based on all stations despite the fact that the stations belonging to humid classes were more in both indices (Table 2). Moreover, in the case of $A I_{U N E P}$, there is only one Humid class $\left(A I_{U N E P}>0.65\right)$ and thus there is no point to compare the performance of $E_{p}$ and $E_{p s}$ from a statistical point of view since their values will always lead to the same classification code/characterization (i.e. Humid). In the case of $A I_{T H}>20$, the same justification of $A I_{U N E P}$ could be used since the detailed division of five humid classes (B1, B2, B3, B4, A) provided by $A I_{T H}$ was proposed for the alternative use of the index as "humidity index" (Thornthwaite, 1948).

\section{[FIGURE 5]}

\section{Discussion}

\subsection{Validity of the derived $C_{t h}$ for periods beyond the calibration period}

The derivation of local $C_{t h}$ coefficients at global scale was performed using the mean monthly grid datasets of 1950-2000 assuming stationary climate conditions, while the validation was performed using stations' raw data from California and Australia that are expanded up to 2016, and stations' raw data from Europe that are expanded up to 2020 (Table S1). The reasons for choosing the specific grid datasets for the derivation of $C_{t h}$ coefficients are the following:

- They are in the form of high-resolution grids (30 arc-sec, $\sim 1 \mathrm{~km}$ at equator), which have been developed using interpolation techniques that include the effects of latitude, longitude and elevation. These grids allow to derive more representative $C_{t h}$ values for every position even when weather stations do not locally exist.

- They cover a large period of time (i.e. 1950-2000) so they can provide more representative mean annual p.w.a. $C_{t h}$ values. The upper threshold of the year 2000 of these grids also allows the validation dataset of stations to be more valid since the larger part of their data is after 2000 and this reduces the possibility of having been used in grids' development.

On the other hand, several works have shown climate differences after 2000 (Hansen et al., 2010; McVicar et al.,

265 2012a,b; Wild et al., 2013; Willet et al., 2014; Sun et al., 2017). Such changes could possibly affect the validity of $C_{t h}$ coefficients and the final estimated values of $E_{r}$ for periods beyond 2000. For this reason, the $C_{t h}$ values and the mean monthly $E_{r}$ values of the grids of Aschonitis et al. (2017) of the period 1950-2000 were extracted from the positions of all 525 stations and compared with the respective values of computed $E_{r}$ and $C_{t h}$ using stations' raw data, which go beyond 2000. The results of this comparison are given in Figs.S3a,b (supplementary material) and clearly show that the gridded $E_{r}$ data and $C_{t h}$ of 19502000 do not show serious deviations from their respective values for periods beyond 2000 allowing their safe use. Moreover, the fact that the original Thornthwaite (1948) formula was built before 1950 using data from the eastern and central USA and 
that the $C_{t h}$ values of the specific territories range between 0.9-1.1 for 1950-2000 (Fig.3), it is not only a verification of the $C_{t h}$ derivation methodology but also an additional indication of a generalized temporal stability of $C_{t h}$.

In the case of Fig.S3b, there is a distinctly deviated $C_{t h}$ pair of values from the 1:1 line (point indicated by a red arow), which is associated to a specific station belonging to the Centro de Investigación Atmosférica de Izaña. This station is an exceptional case since it is at the top of a mountain at $2371 \mathrm{~m}$ a.s.l. in Tenerife island. The derived $C_{t h}$ of this station from the grid of the period 1950-2000 is almost half ( $C_{t h}$ value equal to 1.37) from the one estimated using stations' raw data $\left(C_{t h}\right.$ value equal to 2.44). This large difference is not the result of climate difference before and after 2000 but it is fully justified by the fact that the $C_{t h}$ value of the grid corresponds to an area of $\sim 1 \mathrm{~km}$ while the specific position of the station is at a very unique position, which can be described as the most extreme position within this pixel. There are also 3 stations in Tenerife island at lowland areas where the derived $C_{t h}$ values of 1950-2000 are in agreement with those estimated by the stations' raw data.

\subsection{Scale and other effects on the accuracy of the derived $C_{t h}$}

The case of Izana station in Tenerife was the perfect example for triggering further investigation for the possible effects of scale in similar environments with extremely variable topography. Investigating the individual stations with the larger $\%$ deviation of $E_{p s}$ from $E_{r}$, it was observed a relative systematic deviation in some stations of CIMIS-California database, which are concentrated in the coastline between Los Angeles and San Diego. The specific region is a narrow ( 20-30 km) highly urbanized coastal zone of $\sim 200 \mathrm{~km}$, which is enclosed between the coastline and a hilly/mountainous zone. In the specific stations, the average of $C_{t h}$ values of the period 1950-2000 from the position of these stations was 1.85, while the average of $C_{t h}$ values using their raw data was estimated at 1.46. Apart from the large topographic variation, another reason for the $C_{t h}$ differences in these stations could be the bias that has been removed by clearing extreme flagged wind values in the data of CIMIS database, which are probably associated to hurricane or other extreme events in this region. The coastline region of California is strongly affected by hurricanes and the higher wind speeds during such events may have not been removed by the Sheffield et al. (2006) wind grids that were used by Aschonitis et al. (2017) to build the $E_{r}$ grids. This could justify the fact that the gridded $C_{t h}$ values of 1950-2000 at the positions of the stations are greater than the $C_{t h}$ values estimated by their raw data from CIMIS after removing flagged extreme values.

An additional analysis based only on the stations of California was made to show that a wider regional mean value of $C_{t h}$ coefficient could also be an additional option, especially when the whole territory is described by local $C_{t h}$ coefficients that are only $>1$ or only $<1$ (in California all local $C_{t h}$ coefficients are $>1$ ). For this analysis, the average value of $C_{t h}=1.66$ was estimated based on the values of local $C_{t h}$ coefficients of 1950-2000 from the locations of all stations of CIMIS-California. The mean monthly and mean annual $E_{p s}$ values of these stations were computed using $C_{t h}=1.66$ for all of them and compared with the respective $E_{r}$ values estimated with stations' raw data (Fig.S4a,b, supplementary material). The results of Fig.S4a,b showed that even a regional average of $C_{t h}$ values for California can lead to better results of $E_{p s}$ compared to $E_{p}$ as it was given for monthly and annual estimations in Figs.S1a and S2a, respectively. 
https://doi.org/10.5194/essd-2021-115

Preprint. Discussion started: 9 July 2021

(c) Author(s) 2021. CC BY 4.0 License.

(c) (i)

\subsection{Justifications about the methodology for deriving annual $C_{t h}$ correction coefficients based on partial weighted averages}

The initial trials to derive annual correction coefficients $C_{t h}$ of this study were made using the average value of the twelve monthly $c_{t h, i}$ values of each $i$ month. This procedure led to unreasonably high values due to the extreme high values during winter. An example of this problem based on the gridded data used in the calibration/derivation procedure, is given in Fig. S5a (supplementary material), which corresponds to a position close to Garda Lake in Italy $\left(10.124^{\circ} \mathrm{E}, 45.45^{\circ} \mathrm{N}\right)$. According to Fig.S5a, the annual average of monthly $c_{t h, i}$ values for this location is equal to 2.4 due to the extremely high values during winter and especially January. Using the 2.4 value as annual correction coefficient, the $E_{p s, i}$ value of July becomes equal to $338 \mathrm{~mm}$, which is $203 \mathrm{~mm}$ larger from the respective $E_{r, i}$ value of July (Fig.S5a). The specific procedure for deriving annual

$315 C_{t h}$ coefficients was rejected due to this problem. A second approach was to use the 12 pairs of monthly $E_{r}$ and $E_{p}$ for each position on the grid in order to perform regression analysis based on the form $y=a \cdot x$ without intercept based on the form of $E_{r}=C_{t h} \cdot E_{p}$. An example of the specific procedure is given in Fig.S5b using the data of Fig.S5a, where the annual $C_{t h}$ value was found equal to 0.98 . The specific procedure provides annual $C_{t h}$ values, which are always closer to the monthly coefficients of the warmer months since optimization algorithms try to minimize the total error, which is mainly originated by the months that show larger evapotranspiration values. Despite the fact that the specific procedure pays less attention to the monthly $c_{t h, i}$ values of colder months, it was considered acceptable since most of the hydroclimatic applications require higher accuracy to the larger evapotranspiration values rather to the lower ones.

A similar approach with the one of Fig.S5b was performed by Cristea et al. (2013) for deriving annual correction coefficients for the Priestley-Taylor method for 106 stations across the contiguous USA. The correction coefficients were estimated for each station by minimizing the sum of the squared residuals between Priestley-Taylor and the benchmark FAO56 considering data only for the period April-September (warmer semester). The obtained optimized values of the correction coefficients for each station were then interpolated to produce a map of the Priestley-Taylor correction coefficients. For our study, the specific procedure was found to be extremely demanding in computing requirements since it was impossible to be performed pixel by pixel (777.6 million pixels) with a conventional computer unit for the whole globe using as input 24 rasters of extremely high resolution ( $\sim \mathrm{km})$ with total size of $\sim 70 \mathrm{~GB}$. In order to solve this problem, the method of partial weighted average (Eqs.5-10) developed by Aschonitis et al. (2017) was used, which provides similar results to the regression analysis of $y=a \cdot x$ but allows to perform calculations step by step with a conventional computer unit in GIS environment using large gridded databases. For the data of Fig.S5a, the partial weighted average method provided a $C_{t h}$ value equal to 0.99 , which is almost equal to 0.98 of Fig.S5b. The method of partial weighted average is also extremely efficient since it is not restricted only to the warmer semester or to any other predefined period like the case of Cristea et al. (2013) since it controls all months one by one using the threshold of $45 \mathrm{~mm}$ month $^{-1}$, which is more appropriate for global applications and especially for applications of high-resolution data, giving the appropriate weight to the months with significant values of evapotranspiration.

The threshold of $45 \mathrm{~mm}$ month $^{-1}$ was derived empirically after analysing many datasets using monthly and mean monthly data. In the case of monthly data, a representative example is given in Figs.S6a,b (supplementary material) using the 
monthly data of Embrun station in France $\left(6.50^{\circ} \mathrm{E}, 44.57^{\circ} \mathrm{N}\right) 1980-2020$. Fig. S6a shows the box-whisker plots of monthly $E_{r, i}$ values of the station, while Fig.S6b shows the respective box-whisker plots of monthly $c_{t h, i}$ values. The maximum $c_{t h, i}$ values of December, January and February are outside the plot of Fig. S6b with values 30.1, 129.4 and 210.1, respectively. Figs.S6a,b show that the monthly $c_{t h, i}$ values of months with $E_{r, i}<45 \mathrm{~mm} \mathrm{month}^{-1}$ are extremely unstable and their mean monthly value, even if it seems normal, cannot guarantee its safe use. In the case of mean monthly data, a representative example is given in

345 Figs.7, where the 6300 mean monthly $c_{t h, i}$ values derived by the raw data of the 525 stations were plotted against their respective mean monthly $E_{r}$ values using a 2D density scatter plot. Fig.7 shows that the mean monthly $c_{t h, i}$ values of the stations start to exhibit extremely high dispersion below the threshold of $45 \mathrm{~mm} \mathrm{month}^{-1}$ with values reaching one order of magnitude larger than unity. In the case where there is a location where all months show $E_{r}$ or $E_{p}$ values below $45 \mathrm{~mm} \mathrm{month}{ }^{-1}$, it is suggested either to use the non-zero $C_{t h}$ value of the closer location in the map of Fig.3 or to use directly the original Thornthwaite formula without correction.

\section{[FIGURE 7]}

\section{Data availability}

The produced global database of local $C_{t h}$ coefficients of this study has been archived in PANGAEA and can be assessed using the following link: https://doi.pangaea.de/10.1594/PANGAEA.932638 (Aschonitis et al., 2021). The database is provided at 5 different resolutions (30 arc-sec, 2.5 arc-min, 5 arc-min, 10 arc-min, $0.5 \mathrm{deg}$ ). The coarser resolutions are provided in order to cover the observed resolution range in the initial climatic data used for developing the published $E_{r}$ gridded data by Aschonitis et al. (2017) (e.g., the temperature data of Hijmans et al. (2005) were provided at $30 \mathrm{arc}-\mathrm{sec}$ resolution, while the solar radiation, humidity and wind speed data of Sheffield et al. (2006) were provided at 0.5 deg resolution and rescaled to 30 arc-sec using bilinear interpolation). The data of different resolutions can be used as a tool to assess uncertainties associated to temperature

360 variation effects within different resolution pixels or to estimate average values of the coefficients for larger territories, which have problems at coarse resolutions (e.g., coastlines or islands that do not exist in 0.5 degree resolution) taking into account the concept and concerns of Daly et al. (2006).

\section{Conclusions}

A global database of local correction coefficients for improving the performance of the monthly temperature-based

365 Thornthwaite potential evapotranspiration method was built using gridded data covering the period 1950-2000. The method for developing the correction coefficients was based on partial weighted averages of their respective mean monthly values estimated as the monthly ratios between the benchmark ASCE-standardized $E_{r}$ method (former FAO-56) versus the original Thornthwaite $E_{p}$. The correction coefficients were produced as partial weighted averages of monthly $E_{r} / E_{p}$ ratios by setting the ratios' weight according to the monthly $E_{r}$ magnitude and by excluding colder months because the $E_{r} / E_{p}$ ratio becomes highly 
unstable for low temperatures. The correction coefficients were validated using raw data from 525 stations of California, Australia and Europe that include independent data beyond 2000 up to 2020. The results showed that the corrections coefficients significantly improved the monthly and annual results of original Thornthwaite method $E_{p}$. The use of $E_{p}$ with or without correction coefficients was also evaluated through their use in the aridity indices of Thornthwaite and UNEP versus the respective indices estimated based on the benchmark ASCE-standardized $E_{r}$. The results showed again that the correction coefficients significantly improved the performance of the indices compared to the original Thornthwaite method especially in non-humid environments. The global database of local correction coefficients supports applications of reference evapotranspiration and aridity indices assessment with minimum data requirements (i.e. mean temperature) for locations where climate data are limited. Uncertainties in the values of correction coefficients were observed in regions of high topographic variability and a recommendation for such cases is the use of a regional average of correction coefficients or the use of local

$380 C_{t h}$ values based on the available coarser resolutions provided in the database. The methods and results presented in this study and the observed uncertainties can be used as a base for future works focusing on: (a) the validation of the correction coefficients for other places in the world, (b) comparison with other models of low data requirements, (c) use of the p.w.a. method for recalibrating correction coefficients using station or climate models' data of recent periods.

385 Supplementary material. Supplementary information related to the article is given in the following supplementary file (to be added by the journal).

Author contributions. The idea behind the work was conceived by VA, the data processing was made by V.A and DT while quality control, visualization and writing were completed by VA, DT, MCG, MCV.

Competing interests. The authors declare that they have no conflicts of interest.

Financial support. This research has not received funding.

395 Review statement. This paper was edited by ... and reviewed by .... referees.

\section{References}

Allen, R. G., Walter, I. A., Elliott, R., Howell, T., Itenfisu, D., Jensen, M. and Snyder, R. L.: The ASCE Standardized Reference Evapotranspiration Equation, American Society of Civil Engineers, Idaho., 2005.

Allen, R., Pereira, L., Raes, D. and Smith, M.: Crop evapotranspiration-Guidelines for computing crop water requirementsFAO Irrigation and drainage paper 56, FAO - Food and Agriculture Organization of the United Nations, Rome, Italy. http://www.fao.org/3/X0490E/x0490e00.htm\#Contents, 1998. 
https://doi.org/10.5194/essd-2021-115

Preprint. Discussion started: 9 July 2021

(c) Author(s) 2021. CC BY 4.0 License.

(c) (i)

Almorox, J., Quej, V. H. and Martí, P.: Global performance ranking of temperature-based approaches for evapotranspiration estimation considering Köppen climate classes, J. Hydrol., 528, 514-522, https://doi.org/10.1016/j.jhydrol.2015.06.057, 2015.

Asadi Zarch, M. A., Sivakumar, B. and Sharma, A.: Assessment of global aridity change, J. Hydrol., 520, 300-313, https://doi.org/10.1016/j.jhydrol.2014.11.033, 2015.

Aschonitis, V. G., Papamichail, D., Demertzi, K., Colombani, N., Mastrocicco, M., Ghirardini, A., Castaldelli, G. and Fano, E.-A.: High-resolution global grids of revised Priestley-Taylor and Hargreaves-Samani coefficients for assessing ASCEstandardized reference crop evapotranspiration and solar radiation, Earth Syst. Sci. Data, 9(2), 615-638, https://doi.org/10.5194/essd-9-615-2017, 2017.

Aschonitis, V. G., Touloumidis, D., ten Veldhuis, M.-C., Coenders-Gerrits, M.: Correcting Thornthwaite evapotranspiration formula using a global grid of local coefficients to support temperature-based estimations of reference evapotranspiration and aridity indices, PANGAEA, https://doi.pangaea.de/10.1594/PANGAEA.932638

Baier, W. and Robertson, G. W.: Estimation of latent evaporation from simple weather observations, Can. J. Plant Sci., 45(3), 276-284, https://doi.org/10.4141/cjps65-051, 1965.

Bakundukize, C., Van Camp, M. and Walraevens, K.: Estimation of Groundwater Recharge in Bugesera Region (Burundi) using Soil Moisture Budget Approach, Geol. Belgica, 14(1), 85-102, 2011.

Beguería, S., Vicente-Serrano, S.M., Reig, F., Latorre, B.: Standardized precipitation evapotranspiration index (SPEI) revisited: Parameter fitting, evapotranspiration models, tools, datasets and drought monitoring. Int. J. Climatol., 34 (10), 3001-3023, https://doi.org/10.1002/joc.3887, 2014.

Brinckmann, S., Krähenmann, S., and Bissolli, P.: High-resolution daily gridded data sets of air temperature and wind speed for Europe, Earth Syst. Sci. Data, 8, 491-516, https://doi.org/10.5194/essd-8-491-2016, 2016.

Camargo, A. P., Marin, F. R., Sentelhas, P. C. and Picini, A. G.: Adjust of the Thornthwaite's method to estimate the potential evapotranspiration for arid and superhumid climates, based on daily temperature amplitude, Rev. Bras. Agrometeorol., 7(2), 251-257, 1999.

Castañeda, L. and Rao, P.: Comparison of methods for estimating reference evapotranspiration in Southern California, J. Environ. Hydrol., 13(14), 1-10, 2005.

Cherlet, M., Hutchinson, C., Reynolds, J., Hill, J., Sommer, S. and Von Maltitz, G.: World atlas of desertification rethinking land degradation and sustainable land management, 2018.

430 Cristea, N., Kampf, S., Burges, S. and Asce, F.: Revised Coefficients for Priestley-Taylor and Makkink-Hansen Equations for Estimating Daily Reference Evapotranspiration, J. Hydrol. Eng., 18, 1289-1300, https://doi.org/10.1061/(ASCE)HE.19435584.0000679, 2013.

Dai, A.: Increasing drought under global warming in observations and models, Nat. Clim. Chang., 3, 52-58, https://doi.org/10.1038/nclimate1633, 2013. 
https://doi.org/10.5194/essd-2021-115

Preprint. Discussion started: 9 July 2021

(c) Author(s) 2021. CC BY 4.0 License.

(c) (i)

Daly, C.: Guidelines for assessing the suitability of spatial climate data sets, Int. J. Climatol., 26(6), 707-721, https://doi.org/10.1002/joc.1322, 2006.

Droogers, P. and Allen, R. G.: Estimating Reference Evapotranspiration Under Inaccurate Data Conditions, Irrig. Drain. Syst., 16, 33 - 45, https://doi.org/10.1023/A:1015508322413, 2002.

Hamon, W. R.: Computation of direct runoff amounts from storm rainfall, Int. Assoc. Sci. Hydrol. Publ., 63, 52-62, 1963.

Hamon, W. R.: Estimating Potential Evapotranspiration, J. Hydraul. Div., 87(3), 107-120, 1961.

Hansen, J., Ruedy, R., Sato, M. and Lo, K.: Global Surface Temperature Change, Rev. Geophys., 48(4), 1-29, https://doi.org/10.1029/2010RG000345, 2010.

Hargreaves, G. H. and Samani, Z. A.: Estimating potential evapotranspiration, J. Irrig. Drain. Eng., 108(3), 225-230, 1982.

Harris, I., Jones, P. D., Osborn, T. J., and Lister, D. H.: Updated high-resolution grids of monthly climatic observations-The CRU TS3.10 dataset, Int. J. Climatol., 34(3), 623-642. https://doi.org/10.1002/joc.3711, 2014

Hijmans, R. J., Cameron, S. E., Parra, J. L., Jones, P. G. and Jarvis, A.: Very high resolution interpolated climate surfaces for global land areas, Int. J. Climatol., 25(15), 1965-1978, https://doi.org/10.1002/joc.1276, 2005.

Holdridge, L. R.: Life zone ecology, Tropical Science Center, Costa Rica., 1967.

Jain, P. K. and Sinai, G.: Evapotranspiration Model for Semiarid Regions, J. Irrig. Drain. Eng., 111(4), 369-379, https://doi.org/10.1061/(ASCE)0733-9437(1985)111:4(369), 1985.

Liu, X., Li, C., Zhao, T., Han, L.: Future changes of global potential evapotranspiration simulated from CMIP5 to CMIP6 models, Atmosph. Ocean. Sci. Lett., 13 (6), 568-575. https://doi.org/10.1080/16742834.2020.1824983, 2020

Malmström, V. H.: A New Approach To The Classification Of Climate, J. Geog., 68(6), 351-357, https://doi.org/10.1080/00221346908981131, 1969.

McCloud, D. E.: Water requirements of field crops in Florida as influenced by climate, Proc. Soil Crop Sci. Soc. Florida, 15, 165-172, 1955.

McMahon, T. A., Peel, M. C., Lowe, L., Srikanthan, R. and McVicar, T. R.: Estimating actual, potential, reference crop and pan evaporation using standard meteorological data: A pragmatic synthesis, Hydrol. Earth Syst. Sci., 17(4), 1331-1363, https://doi.org/10.5194/hess-17-1331-2013, 2013.

McVicar, T. R., Roderick, M. L., Donohue, R. J., and Van Niel, T. G.: Less bluster ahead? ecohydrological implications of global trends of terrestrial near-surface wind speeds. Ecohydrology, 5, 381-388, https://doi.org/10.1002/eco.1298 2012a.

McVicar, T. R., Roderick, M. L., Donohue, R. J., Li, L. T., Van Niel, T. G., Thomas, A., Grieser, J., Jhajharia, D., Himri, Y., Mahowald, N. M., Mescherskaya, A. V, Kruger, A. C., Rehman, S. and Dinpashoh, Y.: Global review and synthesis of trends in observed terrestrial near-surface wind speeds: Implications for evaporation, J. Hydrol., 416-417, 182-205, https://doi.org/https://doi.org/10.1016/j.jhydrol.2011.10.024, 2012b.

Osborn, T. J. and Jones, P. D.: The CRUTEM4 land-surface air temperature data set: construction, previous versions and dissemination via Google Earth, Earth Syst. Sci. Data, 6, 61-68, https://doi.org/10.5194/essd-6-61-2014, 2014. 
https://doi.org/10.5194/essd-2021-115

Preprint. Discussion started: 9 July 2021

(c) Author(s) 2021. CC BY 4.0 License.

(c) (i)

Oudin, L., Hervieu, F., Michel, C., Perrin, C., Andréassian, A., Anctil, F. and Loumagne, C.: Which potential evapotranspiration input for a lumped rainfall-runoff model?: Part 2-Towards a simple and efficient potential evapotranspiration model for rainfall-runoff modelling, J. Hydrol., 303(1-4), 290-306, https://doi.org/10.1016/j.jhydrol.2004.08.026, 2005.

Palmer, W.: Meteorological Drought. Research paper no.45, U.S. Department of Commerce Weather Bureau, Washington D.C., 1965.

Peel, M. C., Finlayson, B. L. and McMahon, T. A.: Updated world map of the Köppen-Geiger climate classification, Hydrol. Earth Syst. Sci., 11(5), 1633-1644, https://doi.org/10.5194/hess-11-1633-2007, 2007.

Penman, H. L.: Natural evaporation from open water, hare soil and grass, Proc. R. Soc. Lond. A. Math. Phys. Sci., 193(1032), 120-145, https://doi.org/10.1098/rspa.1948.0037, 1948.

Pereira, A. R. and Pruitt, W. O.: Adaptation of the Thornthwaite scheme for estimating daily reference evapotranspiration, Agric. Water Manag., 66(3), 251-257, https://doi.org/10.1016/j.agwat.2003.11.003, 2004.

Quej, V. H., Almorox, J., Arnaldo, J. A. and Moratiel, R.: Evaluation of Temperature-Based Methods for the Estimation of Reference Evapotranspiration in the Yucatán Peninsula, Mexico, J. Hydrol. Eng., 24(2), 05018029-1-05018029-10, https://doi.org/10.1061/(ASCE) HE.1943-5584.0001747, 2019.

Sanikhani, H., Kisi, O., Maroufpoor, E. and Yaseen, Z. M.: Temperature-based modeling of reference evapotranspiration using several artificial intelligence models: application of different modeling scenarios, Theor. Appl. Climatol., 135(1), 449-462, https://doi.org/10.1007/s00704-018-2390-z, 2019.

Sheffield, J., Goteti, G. and Wood, E. F.: Development of a 50-Year High-Resolution Global Dataset of Meteorological Forcings for Land Surface Modeling, J. Clim., 19(13), 3088-3111, https://doi.org/10.1175/JCLI3790.1, 2006.

Sheffield, J., Wood, E. F. and Roderick, M. L.: Little change in global drought over the past 60 years, Nature, 491(7424), 435438, https://doi.org/10.1038/nature11575, 2012.

490 Shuttleworth, W. J.: Evaporation. Handbook of Hydrology, 41 (1), 505-572, https://doi.org/10.1021/ie50529a034, 1993.

Sun, X., Ren, G., Xu, W., Li, Q. and Ren, Y.: Global land-surface air temperature change based on the new CMA GLSAT data set, Sci. Bull., 62(4), 236-238, https://doi.org/10.1016/j.scib.2017.01.017, 2017.

Thornthwaite, C.: An Approach toward a Rational Classification of Climate, Geogr. Rev., 38(1), 55-94, https://doi.org/10.2307/210739, 1948.

495 Trajkovic, S.: Temperature-Based Approaches for Estimating Reference Evapotranspiration, J. Irrig. Drain. Eng., 131(4), 316323, https://doi.org/10.1061/(asce)0733-9437(2005)131:4(316), 2005.

Trajkovic, S.: Hargreaves versus Penman-Monteith under Humid Conditions, J. Irrig. Drain. Eng., 133(1), 38-42, https://doi.org/10.1061/(asce)0733-9437(2007)133:1(38), 2007.

Trajkovic, S. and Kolakovic, S.: Estimating reference evapotranspiration using limited weather data, J. Irrig. Drain. Eng., 135(4), 443-449, https://doi.org/10.1061/(ASCE)IR.1943-4774.0000094, 2009a. 
https://doi.org/10.5194/essd-2021-115

Preprint. Discussion started: 9 July 2021

(c) Author(s) 2021. CC BY 4.0 License.

(c) (i)

Trajkovic, S. and Kolakovic, S.: Evaluation of reference evapotranspiration equations under humid conditions, Water Resour. Manag., 23(14), 3057-3067, https://doi.org/10.1007/s11269-009-9423-4, 2009b.

Trajkovic, S., Gocic, M., Pongracz, R., Bartholy, J. and Milanovic, M.: Assessment of Reference Evapotranspiration by Regionally Calibrated Temperature-Based Equations, KSCE J. Civ. Eng., 24(3), 1020-1027, https://doi.org/10.1007/s12205-020-1698-2, 2020.

Trenberth, K. E., Dai, A., van der Schrier, G., Jones, P. D., Barichivich, J., Briffa, K. R. and Sheffield, J.: Global warming and changes in drought, Nat. Clim. Chang., 4(1), 17-22, https://doi.org/10.1038/nclimate2067, 2014.

UNEP: World atlas of desertification (United nations environment programme), 2nd ed., London., 1992.

Van Der Schrier, G., Jones, P.D., Briffa, K.R.: The sensitivity of the PDSI to the Thornthwaite and Penman-Monteith parameterizations for potential evapotranspiration, J. Geophys. Res. Atmos., 116(3), art. no. D03106, https://doi.org/ 10.1029/2010JD015001, 2011.

Van Der Schrier, G., Barichivich, J., Briffa, K. R. and Jones, P. D.: A scPDSI-based global data set of dry and wet spells for 1901-2009, J. Geophys. Res. Atmos., 118(10), 4025-4048, https://doi.org/10.1002/jgrd.50355, 2013.

Wang, K. and Dickinson, R. E.: A review of global terrestrial evapotranspiration: Observation, modeling, climatology, and climatic variability, Rev. Geophys., 50(2), RG2005, https://doi.org/10.1029/2011RG000373, 2012.

Weiß, M. and Menzel, L.: A global comparison of four potential evapotranspiration equations and their relevance to stream flow modelling in semi-arid environments, Adv. Geosci., 18, 15-23, https://doi.org/10.5194/adgeo-18-15-2008, 2008.

Wild, M., Folini, D., Schär, C., Loeb, N., Dutton, E. G. and König-Langlo, G.: The global energy balance from a surface perspective, Clim. Dyn., 40(11), 3107-3134, https://doi.org/10.1007/s00382-012-1569-8, 2013.

Willett, K. M., Dunn, R. J. H., Thorne, P. W., Bell, S., de Podesta, M., Parker, D. E., Jones, P. D. and Williams Jr., C. N.: HadISDH land surface multi-variable humidity and temperature record for climate monitoring, Clim. Past, 10(6), 19832006, https://doi.org/10.5194/cp-10-1983-2014, 2014.

Willmott, C. J., Rowe, C. M. and Mintz, Y.: Climatology of the terrestrial seasonal water cycle, J. Climatol., 5(6), 589-606, https://doi.org/10.1002/joc.3370050602, 1985.

Yang, Q., Ma, Z., Zheng, Z. and Duan, Y.: Sensitivity of potential evapotranspiration estimation to the Thornthwaite and Penman-Monteith methods in the study of global drylands, Adv. Atmos. Sci., 34(12), 1381-1394, https://doi.org/10.1007/s00376-017-6313-1, 2017.

Yuan, S. and Quiring, S. M.: Drought in the U.S. Great Plains (1980-2012): A sensitivity study using different methods for estimating potential evapotranspiration in the Palmer Drought Severity Index, J. Geophys. Res. Atmos., 119(19), 1099611010, https://doi.org/10.1002/2014jd021970, 2014.

Zhang, Y., Liu, S., Wei, X., Liu, J. and Zhang, G.: Potential Impact of Afforestation on Water Yield in the Sub-Alpine Region of Southwestern China, JAWRA J. Am. Water Resour. Assoc., 44(5), 1144-1153, https://doi.org/10.1111/j.17521688.2008.00239.x, 2008. 
https://doi.org/10.5194/essd-2021-115

Preprint. Discussion started: 9 July 2021

(c) Author(s) 2021. CC BY 4.0 License.

(c) (i)

Zhang, J., Sun, F., Xu, J., Yaning, C., Sang, Y.-F. and Liu, C.: Dependence of trends in and sensitivity of drought over China (1961-2013) on potential evaporation model, Geophys. Res. Lett., 43(1), 206-213, https://doi.org/10.1002/2015GL067473, 2015.

Zomer, R. J., Trabucco, A., Bossio, D. A., van Straaten, O., and Verchot, L. V.: Climate change mitigation: A spatial analysis of global land suitability for clean development mechanism afforestation and reforestation. Agr. Ecosyst. Environ, 126, 67-80, https://doi.org/10.1016/j.agee.2008.01.0142008.

540

\section{Tables}

Table 1. Statistical metrics (Eqs.12-16) for the comparisons between $E_{p}$ vs. $E_{r}$ and $E_{p s}$ vs. $E_{r}$ for CIMIS-California, AGBMAustralia and ECAD-Europe stations (the unit for MAE, ME, RMSE is mm month ${ }^{-1}$ ).

\begin{tabular}{lcccccc}
\hline & \multicolumn{2}{c}{ California } & \multicolumn{2}{c}{ Australia } & \multicolumn{2}{c}{ Europe } \\
& $E_{p}$ vs. $E_{r}$ & $E_{p s}$ vs. $E_{r}$ & $E_{p}$ vs. $E_{r}$ & $E_{p s}$ vs. $E_{r}$ & $E_{p}$ vs. $E_{r}$ & $E_{p s}$ vs. $E_{r}$ \\
\hline No. records & 720 & 720 & 960 & 960 & 4620 & 4620 \\
$M A E$ & 40.3 & 22.6 & 64.6 & 45.2 & 14.5 & 11.9 \\
$M E$ & -39.7 & 4.1 & -60.5 & 17.3 & -7.4 & -6.9 \\
$R M S E$ & 46.4 & 31.0 & 74.2 & 63.7 & 20.1 & 15.3 \\
$R_{S q r}$ & 0.852 & 0.858 & 0.624 & 0.746 & 0.824 & 0.919 \\
$d$ & 0.847 & 0.948 & 0.743 & 0.867 & 0.945 & 0.972 \\
\hline \multicolumn{7}{r}{} \\
No. records & 60 & 60 & Metrics based on mean annual values & & \\
$M A E$ & 476.2 & 142.1 & 730.5 & 256.8 & 116.6 & 101.6 \\
$M E$ & -476.2 & 49.8 & -726.5 & 208.0 & -89.3 & -83.1 \\
$R M S E$ & 500.1 & 177.9 & 800.2 & 317.0 & 184.7 & 126.0 \\
$R_{S q r}$ & 0.717 & 0.603 & 0.526 & 0.812 & 0.785 & 0.879 \\
$d$ & 0.501 & 0.845 & 0.571 & 0.906 & 0.728 & 0.94 \\
\hline
\end{tabular}


https://doi.org/10.5194/essd-2021-115

Preprint. Discussion started: 9 July 2021

(c) Author(s) 2021. CC BY 4.0 License.

Table 2. Statistical metrics (Eqs.12-16) for the comparisons between $E_{p}$ vs. $E_{r}$ and $E_{p s}$ vs. $E_{r}$ when they are applied in the (a) $A I_{U N E P}$ and (b) $A I_{T H}$ aridity indices by dividing the 525 stations to two groups based on non-humid or humid classes of each index (MAE, ME, RMSE are unitless as the indices).

\begin{tabular}{|c|c|c|c|c|}
\hline & $E_{p}$ vs. $E_{r}$ & $E_{p s}$ vs. $E_{r}$ & $E_{p}$ vs. $E_{r}$ & $E_{p s}$ vs. $E_{r}$ \\
\hline (a) & \multicolumn{2}{|c|}{ Stations with $A I_{U N E P} \leq 0.65^{*}$ (non-humid) } & \multicolumn{2}{|c|}{ Stations with $A I_{U N E P}>0.65^{*}$ (humid) } \\
\hline No. stations & 197 & 197 & 328 & 328 \\
\hline$M A E$ & 0.169 & 0.036 & 0.151 & 0.264 \\
\hline$M E$ & 0.169 & 0.003 & 0.035 & 0.233 \\
\hline$R M S E$ & 0.194 & 0.056 & 0.264 & 0.376 \\
\hline$R_{S q r}$ & 0.867 & 0.893 & 0.875 & 0.932 \\
\hline$d$ & 0.773 & 0.969 & 0.963 & 0.950 \\
\hline (b) & \multicolumn{2}{|c|}{ Stations with $A I_{T H} \leq 20^{*}$ (non-humid) } & \multicolumn{2}{|c|}{ Stations with $A I_{T H}>20^{*}$ (humid) } \\
\hline No. stations & 257 & 257 & 268 & 268 \\
\hline$M A E$ & 12.8 & 6.3 & 14.9 & 26.7 \\
\hline$M E$ & 12.7 & 3.6 & 3.0 & 24.2 \\
\hline$R M S E$ & 15.1 & 10.0 & 26.6 & 39.4 \\
\hline$R_{S q r}$ & 0.842 & 0.882 & 0.872 & 0.928 \\
\hline$d$ & 0.855 & 0.939 & 0.962 & 0.945 \\
\hline
\end{tabular}

*estimated by the benchmark $E_{r}$. 
https://doi.org/10.5194/essd-2021-115

Preprint. Discussion started: 9 July 2021

(c) Author(s) 2021. CC BY 4.0 License.

(c) (i)

\section{FIGURES}

(a)
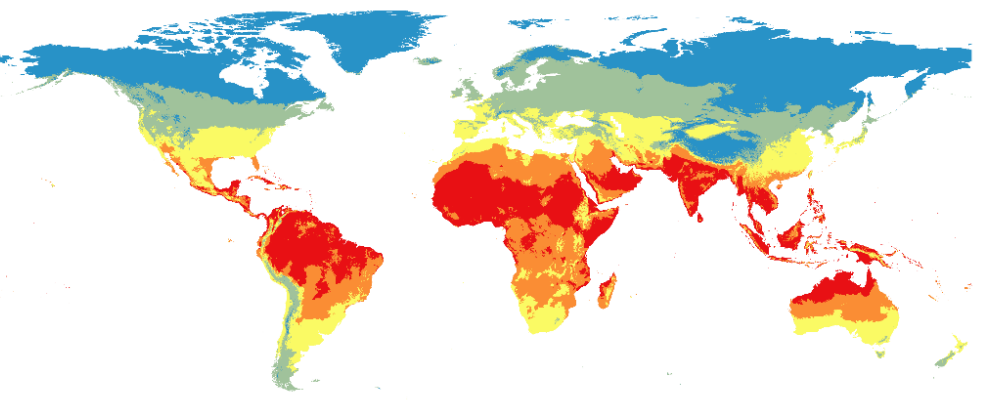

$T_{\text {mean }}$

$\left({ }^{\circ} \mathrm{C}\right)$

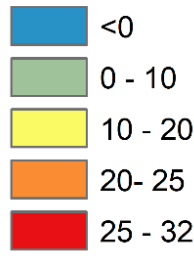

(b)
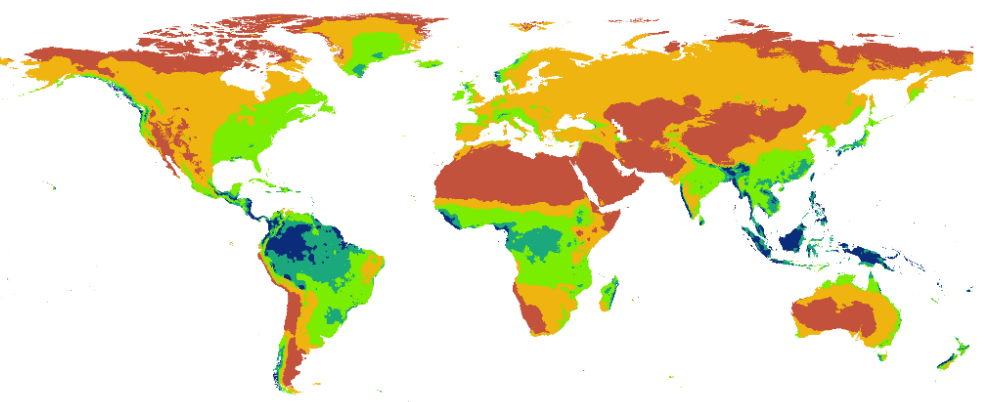

(c)

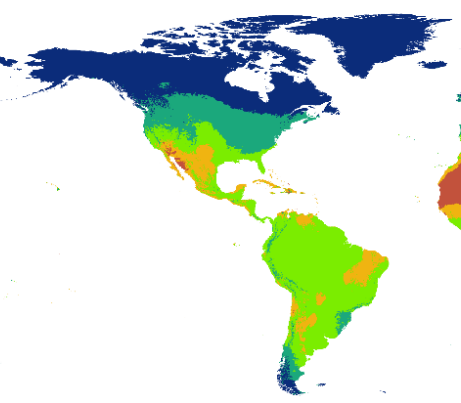

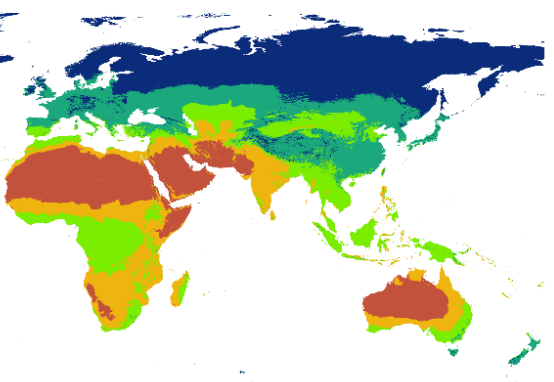

$P$

$\left(\mathrm{mm}\right.$ year $\left.{ }^{-1}\right)$

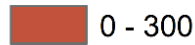

$300-800$

$\square 800-1,600$

$1,600-2,500$

$2,500-11,401$

$E_{r}$ $\left(\mathrm{mm}\right.$ year ${ }^{-1}$ )

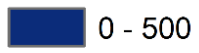

$500-1,000$

$1,000-1,500$

$\square 1,500-2,000$

$2,000-3,135$

Figure 1. (a) Mean annual temperature for the period (Hijmans et al., 2005), (b) Mean annual precipitation for the period (Hijmans et al., 2005), (c) mean annual reference evapotranspiration of ASCE-standardized method for short reference crop for the period (Aschonitis et al., 2017) of 1950-2000. 

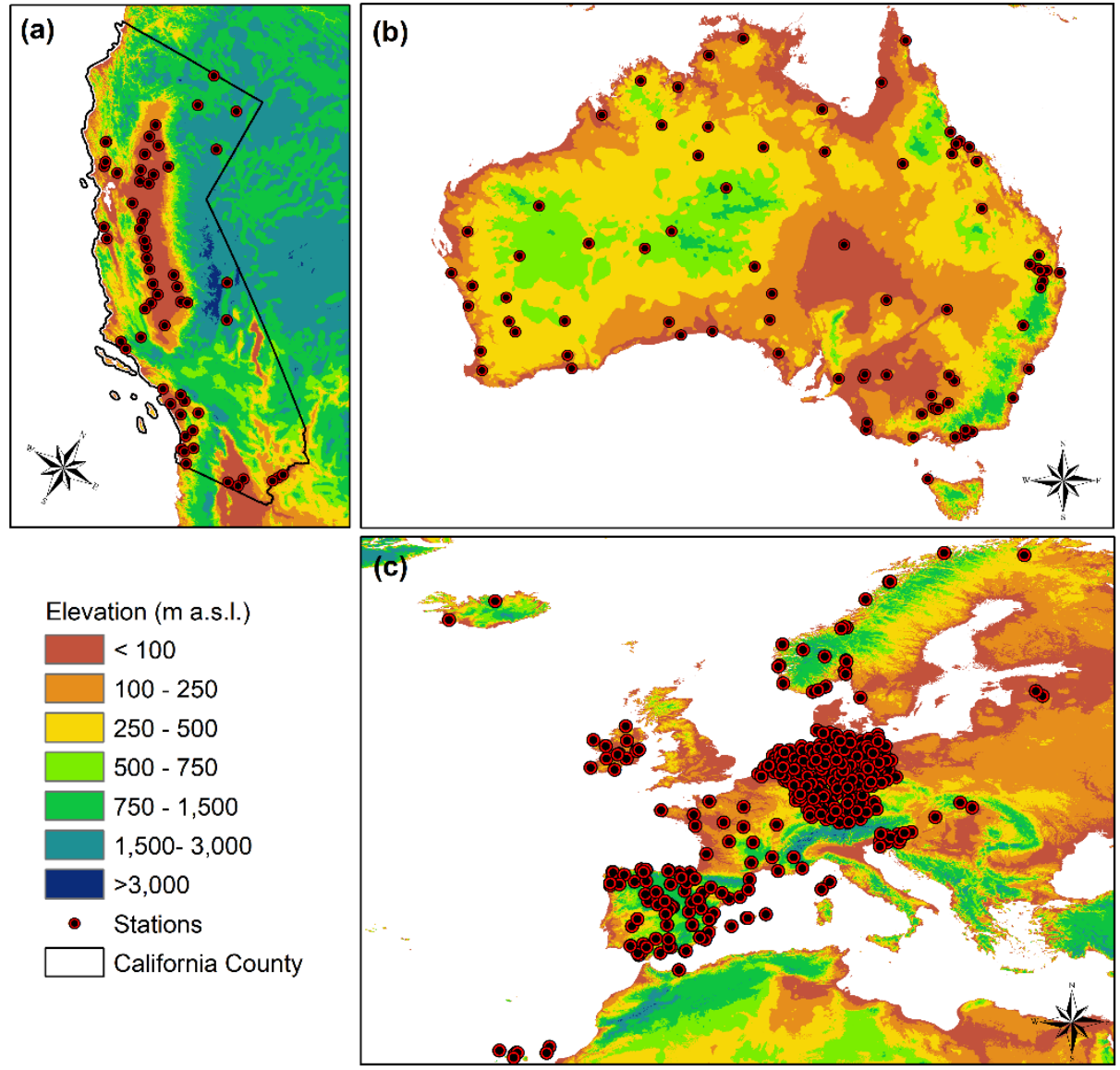

Figure 2. (a) 60 stations of California from CIMIS database, (b) 80 stations of Australia from AGBM database, and (c) 385 stations of Europe from ECAD database.
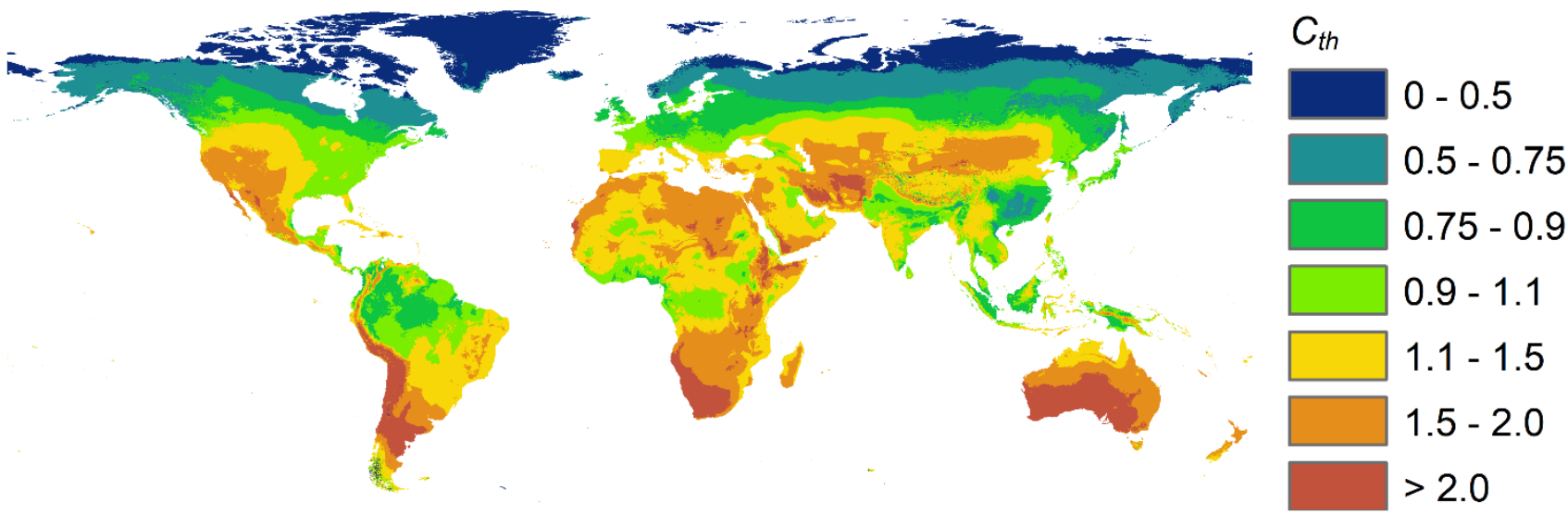

Figure 3. Global map of the annual partial weighted average $C_{t h}$ coefficients. 

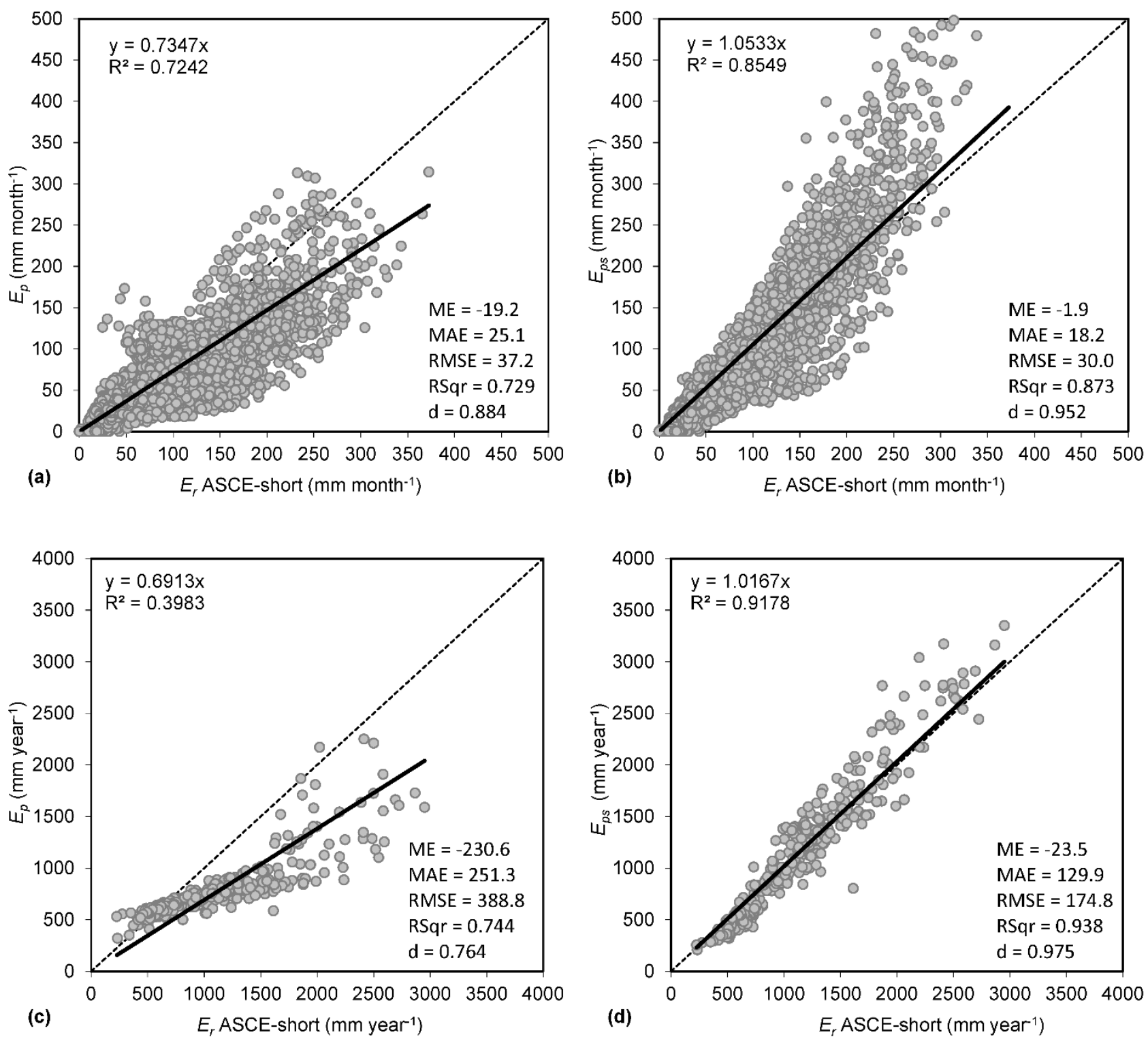

Figure 4. (a) 1:1 plots of mean monthly $E_{p}$ versus mean monthly $E_{r}$, (b) mean monthly $E_{p s}$ versus mean monthly $E_{r}$, (c) mean annual $E_{p}$ versus annual monthly $E_{r}$, (d) mean annual $E_{p s}$ versus annual monthly $E_{r}$, using the data of all 525 stations from the three databases of CIMIS, AGBM, ECAD. 

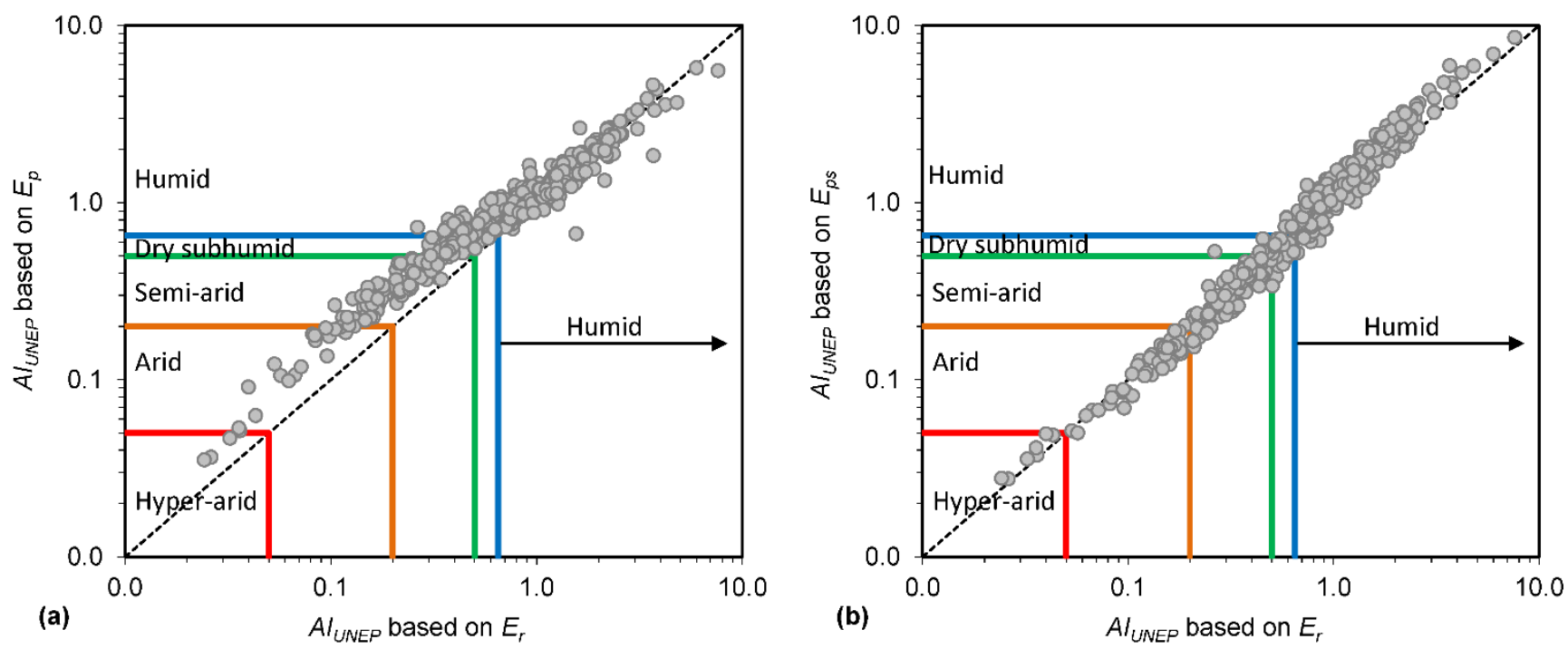

Figure 5. (a) $1: 1 \log -\log$ plots of $A I_{U N E P}$ using mean monthly $E_{p}$ versus $A I_{U N E P}$ using mean monthly $E_{r}$, (b) $A I_{U N E P}$ using mean 610 monthly $E_{p s}$ versus mean monthly $E_{r}$ using the data of all 525 stations from the three databases of CIMIS, AGBM, ECAD.
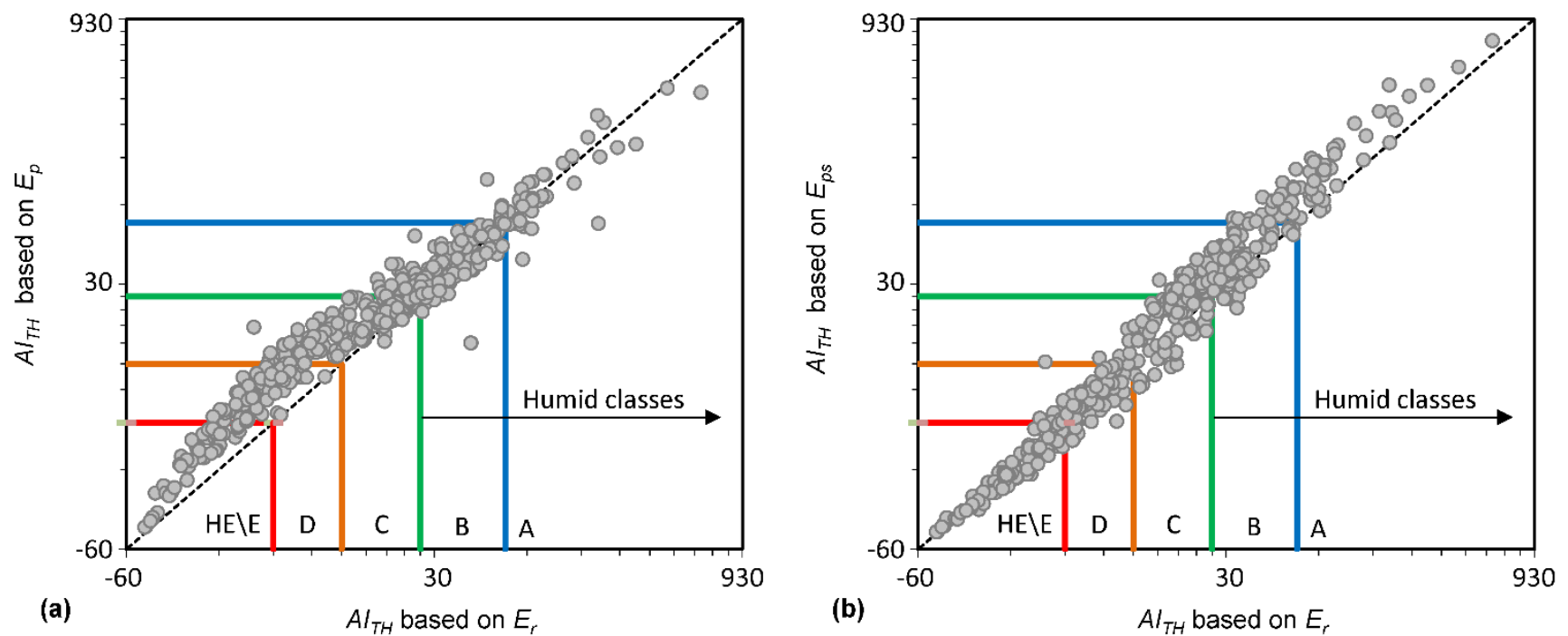

Figure 6. (a) $1: 1 \log -\log$ plots of $A I_{T H}$ using mean monthly $E_{p}$ versus $A I_{T H}$ using mean monthly $E_{r}$, (b) $A I_{T H}$ using mean monthly $E_{p s}$ versus mean monthly $A I_{T H}$ using the data of all 525 stations from the three databases of CIMIS, AGBM, ECAD. 
https://doi.org/10.5194/essd-2021-115

Preprint. Discussion started: 9 July 2021

(c) Author(s) 2021. CC BY 4.0 License.

(c) (i)

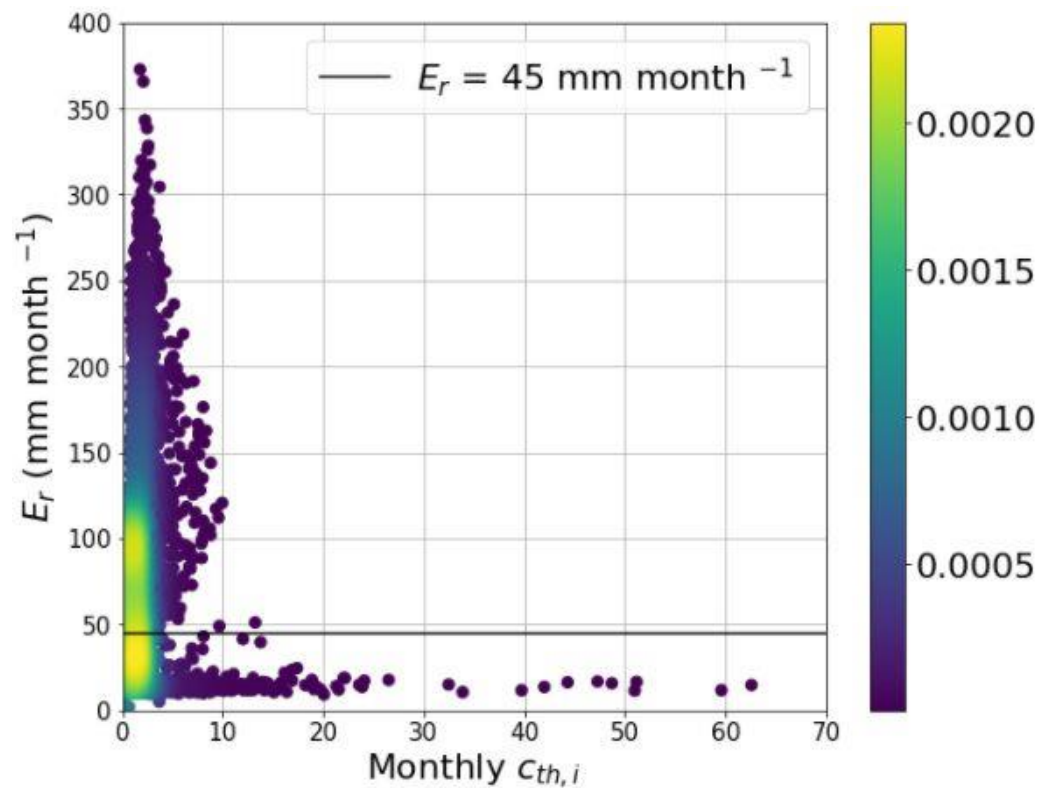

Figure 7. 2D scatter density plot between the 6300 mean monthly $c_{t h, i}$ values versus the respective mean monthly $E_{r}$ values 630 derived by the raw data of the 525 stations ( $c_{t h, i}=0$ or non-defined due to $E_{r}$ and/or $E_{p}=0$ were not included in the graph). 